\title{
A Thermo-Chemo-Mechanical Model for Concrete. I: Hydration and Aging
}

\author{
Miguel Cervera, ${ }^{*}$ Javier Oliver ${ }^{\dagger}$ and Tomás Prato ${ }^{\ddagger}$
}

\begin{abstract}
In this work a coupled thermo-chemo-mechanical model for the behaviour of concrete at early ages is proposed. The model allows to simulate the observed phenomena of hydration, aging, damage and creep. It is formulated within a consistent thermodynamic framework, from which the state equations are derived. In this first part the formulation and assessment of the thermo-chemical aspects of the model are presented. It is based on the Reactive Porous Media Theory, and it can accurately predict the evolution in time of the hydration degree and the hydration heat production. The evolution of the compressive and tensile strengths and elastic moduli is related to the aging degree, a concept introduced to account for the effect of the curing temperature in the evolution of the mechanical properties. The short and long term mechanical behaviour is modelled via a viscoelastic damage model which accounts for the aging effects. The formulation and assessment of the mechanical part of the model are relegated to a companion paper that follows.
\end{abstract}

\footnotetext{
${ }^{*}$ Asst. Prof. Struc. Anal., ETS Ingenieros de Caminos, 08034 Barcelona, Spain.

${ }^{\dagger}$ Prof. Cont. Mech., ETS Ingenieros de Caminos, 08034 Barcelona, Spain.

${ }^{\ddagger}$ Grad. Res. Asst., ETS Ingenieros de Caminos, 08034 Barcelona, Spain.
} 


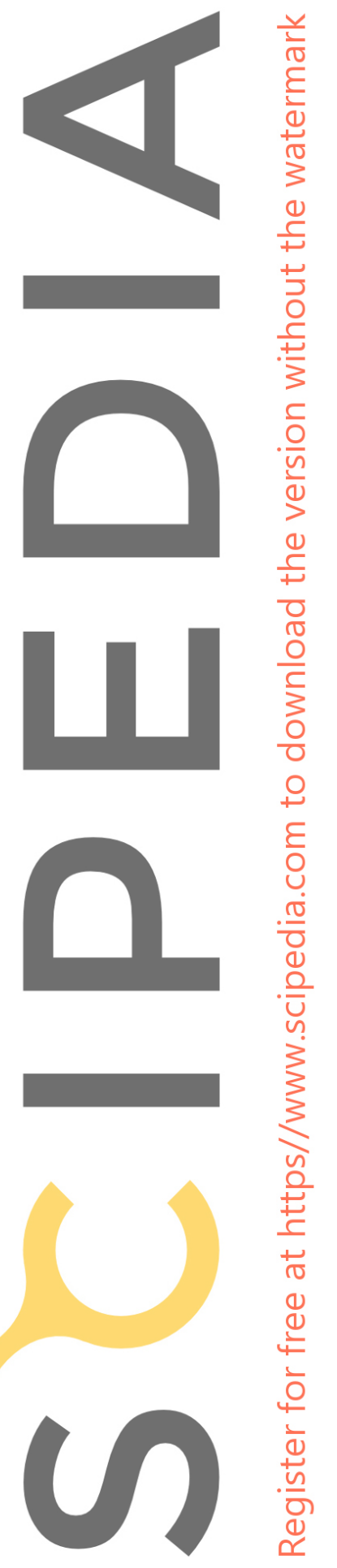




\section{INTRODUCTION}

Quality control during construction is one of the challenges of todays engineering practice, both with regard to the loss of durability and functionality of the structures being built. In concrete technology, cracking is a cause of major concern, and it is primarily associated with thermal (and shrinkage) effects, specially at early ages.

The chemical processes associated to the hardening of young concrete in the first days after casting are accompanied by significant temperature and volume changes. Initially, the reaction of hydration is highly exothermal, and the heat generated may produce an increment of temperature up to $50-60^{\circ} \mathrm{C}$ under adiabatic conditions. As the stiffness of concrete is then quite low, this usually leads to moderate, and mainly compressive, stresses. Later, when the stiffness has significantly increased, the concrete starts to cool down. The low conductivity of the material, differential effects due to the evolubive constr $\frac{v}{\widetilde{H}}$ ction process and convection phenomena with the enviroment mar generase considerable thermal gradients. These, together with gecmetrical aspectseand external restraints may develop relatively important tensile stresse at this early age and cracking may appear. This may result in structural damage even befor the structure is loaded and, in any case, it may affect significantly the durability and serviceability of massive and reinforced fect significantly the dura

To monitor thișype of phenomena a coupled thermo-chemo-mechanical model is keeded to 3 rovide information on: the progress of the hydration process, the associsted temperature rises, the evolution of the concrete trength and stiffrioss, as well as the development of tensile stresses and the possibility of c1 ${ }^{\bar{Q}}$ cking during the construction process.

This paper presonts a thermo-chemo-mechanical model which considers many of the releverat features of the hydration and aging of concrete, in a format suitable $\bar{F}_{r}$ its implementation in the general framework of the

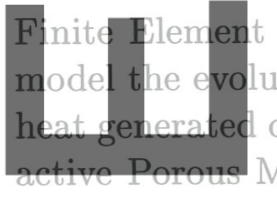

assumption of a ctorst

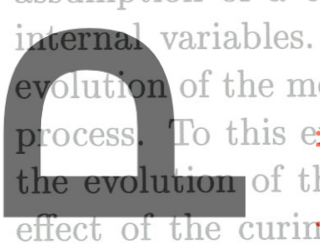

realistic manner t]

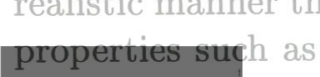

lated to the compi

Finally, different à

observed behavioufof conventional and high-performance concrete mixes at early ages with thesimulations obtained using the proposed model. 


\section{HYDRATION MODEL}

Hydration of concrete is a very complex process which involves quite a number of chemical and physical phenomena at the microscopic level. Basically, the free water present in the mixture reacts with the unhydrated cement to form hydrates. Portland cement is formed by four main mineral constituents: calcium silicates like $C_{3} S$ and $C_{2} S$, calcium aluminates like $C_{3} A$ and calcium aluminoferrites like $C_{4} A F$. They react and combine with water to form differents hydrates: calcium silicate hydrate $C S H$, calcium hydroxide $C H$, ettringite $A f t$, monosulfate $A f m$, etc. The hydration mechanisms have been investigated for the last hundred years, but they are not clearly understood. However, it is clear that the rates of reaction of the individual constituents differ quite significantly. Therefore, the mathematical modelling of the interaction in a hydrating poly-mineral and poly-size system is very complicafed, as, chemical, physical, stereological and granular aspects have to be consider है. These complications make it mandatory to consider the pheronenon of linker: hydration rather than hydration of the individual compounds, and to state the problem in terms of the apparent, overall hydration process (

In view of this evidence, a macroscopic description of the hydration phenomenon is adoted for engineering purposes. From this point of view, hydration of concre is a highly exothermic and thermally activated reaction, so that a thermo-chemical model is necessary for its modellization. State variables nee must be previded to establish the relevant state equations.

The therno-chered model used in this work is based on the theory (chemo-plastic) $\bar{Q}$ soncrete as proposed by Ulm and Coussy $(1995,1996)$. Within this frameroork, the hydration process of concrete can be viewed, from a macroscop level, as a chemical reaction in which the free water is a reactant phase्owhich combines with the unhydrated cement to form combined wa
(nicro) diffus
be considered nhe hydrates as a product phase. This implies that the ater through the layers of already formed hydrates can o dominant mechanism in the kinetics of the reaction.

Hydration Extęint

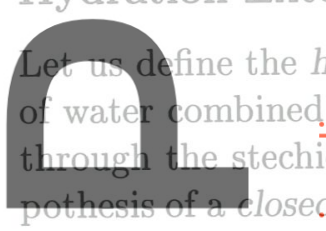

Q $d r a t i o n$ (or reaction) extent, $\chi$, as the number of moles क्षer unit volume (related to the mass of water combined ginetric relationships and the molar masses). In the hysechemical system, that is, without external supply or loss of water, the hydrontion extent can be considered as an internal variable of the system.

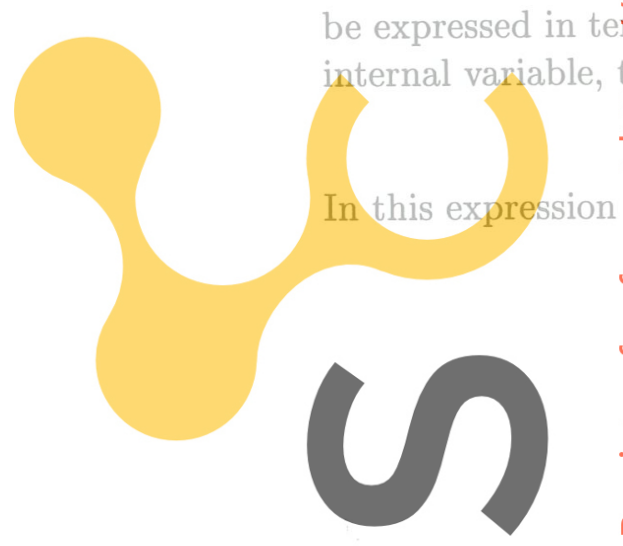

the free energy for the thermo-chemical system can of one external variable, the temperature $T$, and one Q hydration extent $\chi$ :

$=\Psi(T, \chi)=V(T)+L(T, \chi)+H(\chi)$

is the thermal contribution

$V(T)=-\frac{1}{2} \frac{C}{T_{0}}\left(T-T_{0}\right)^{2}$ 
where $T_{0}$ is the initial temperature and $C$ is the heat capacity per unit volume (in a stress free experiment), which can be assumed to be a constant material property, that is, independent on temperature and the hydration extent. The thermo-chemical coupling is represented by $L$, with the expression

$$
L(T, \chi)=\frac{Q(\chi)}{T_{0}}\left(T-T_{0}\right)
$$

where $Q(\chi)$ represents the amount of heat liberated per unit volume as a function of the reaction extent (in a stress free and isothermal experiment). Most authors (Reinhard et al. 1982; Rostassy et al. 1993; Torrenti et al. 1994; de Schutter and Taerwe 1995) identify the rate of heat liberation with the rate of hydration. This is equivalent to assume a linear dependency of the form

$$
Q(\chi)=Q_{\chi} \chi
$$

where $Q_{\chi}$ is the latent heat per unit of hydration extent, here assumed a taken as a cubic fu 1 pit̄perty.

Ehe chemical contribution, which in this work will be Eision such as

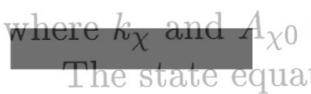

material properties and $\chi_{\infty}$ is the final value of $\chi$.

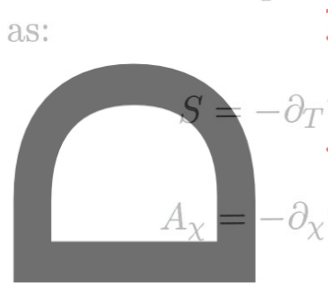

where $S$ is the entron and $A_{\chi}$ is the chemical affinity of the reaction, the thermodynamical
extent, respectivel
cations, the last te
$A_{\chi 0}$ is the initial
$A_{\chi}=0$ for $\chi=\chi$ On the usual range of temperatures for concrete appliin Eq. (7), $-\partial_{\chi} L$, is considered negligible. Note that Onity of the reaction (at $\chi=0$ and $T=T_{0}$ ) and that o $\left(\right.$ at $\left.T=T_{0}\right)$. Note also that setting $k_{\chi}=0$ a linear $A_{\chi}-\chi$ relationship is established (Ulm and Coussy 1995).

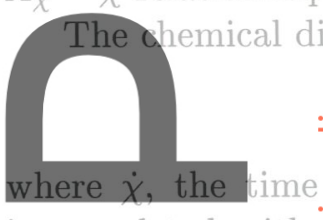

ipation can then be expressed as:

$\frac{\text { 뭉 }}{0} \mathcal{D}_{\text {chem }}=A_{\chi} \dot{\chi} \geq 0$ is completed with $\bar{H}_{\text {le }}$ evolution equation for the internal variable. The hydration rate is pionortional to the chemical affinity, and it is usual to assume that the hys Arrhenius type equ 3 wion such as

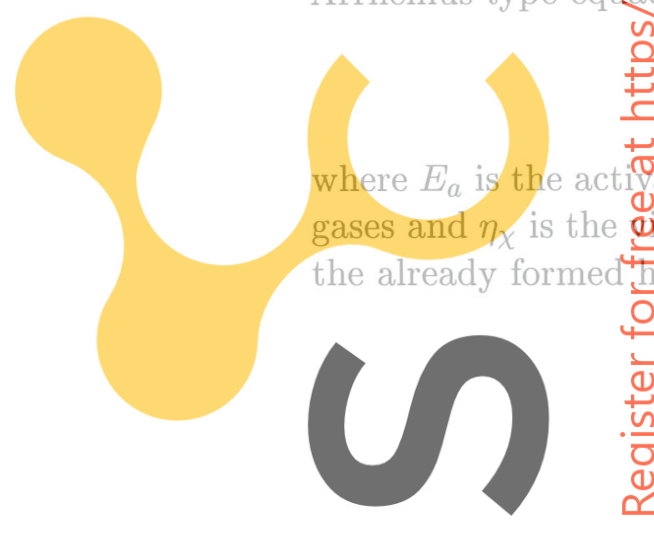

$$
\dot{\chi}=\frac{A_{\chi}}{\eta_{\chi}} \exp \left(-\frac{E_{a}}{R T}\right)
$$

ation energy of the reaction, $R$ is the constant for ideal iscosity due to microdiffusion of the free water through thydrates. 
The ratio $E_{a} / R$ can be experimentally determined, and it ranges from 3000 to $8000{ }^{\circ} \mathrm{K}$ for concrete. Hansen and Nielsen (1985) and van Breugel (1992a) found that the apparent activation energy decreases with temperature, but it remains mostly constant above $20^{\circ} \mathrm{C}$.

The viscosity $\eta_{\chi}$ is an increasing function of $\chi$, since the growth of the layers of hydrates increases the diffussion time of the free water to reach the unhydrated cement. Inspired in de Schutter and Taerwe (1995), it is here proposed to consider $\eta_{\chi}=\eta_{\chi}(\chi)$ so that

$$
\eta_{\chi}=\eta_{\chi 0} \exp \left(\bar{\eta} \frac{\chi}{\chi_{\infty}}\right)
$$

where $\eta_{\chi 0}$ and $\bar{\eta}$ are material constants. Note that the chemical dissipation can then be expressed as

$$
\begin{aligned}
& \mathcal{D}_{\text {che }}=\frac{A_{\chi}^{2}}{\eta_{\chi_{0}}} \exp \left(-\bar{\eta} \frac{\chi}{\chi_{\infty}}\right) \exp \left(-\frac{E_{a}}{R T}\right) \geq 0 \\
& \text { whiek is automatic 量ly satisfied if } \eta_{\chi_{0}} \geq 0 \text {. Now, using Eq. (10), Eq. (9) } \\
& \begin{array}{l}
\text { may bewritten as } \\
\qquad \dot{\chi}=\frac{k_{\chi}}{\eta_{\chi 0}}\left(\frac{A_{\chi 0}}{k_{\chi \chi} \chi}\right. \\
\text { where it can be see }
\end{array} \\
& \stackrel{\Perp}{\leftarrow}+\chi)\left(\chi_{\infty}-\chi\right) \exp \left(-\bar{\eta} \frac{\chi}{\chi_{\infty}}\right) \exp \left(-\frac{E_{a}}{R T}\right) \geq 0 \\
& \text { the reaction slows } \frac{\text { Hen }}{3} \text { and } \dot{\chi} \text { tends to vanish. }
\end{aligned}
$$

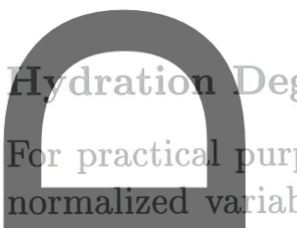

ges, it is convenient to rewrite the model in terms of a called. hydration degree, defined as $\xi=\chi / \bar{\chi}_{\infty}$, where $\bar{\chi}_{\infty}$ is the final vate of $\chi$ in ideal conditions, that is, with an adequate water/cement ratio $\frac{\Phi_{0}}{\mathrm{O}}$ ensure full hydration and perfect contact between the water and the cem@t grains. In practice, these conditions are not fulfilled during curing and fomplete hydration of the concrete is not achieved, so $\chi_{\infty}<\bar{\chi}_{\infty}$ and, theofore, $\xi_{\infty}<1$ (Bentz et al. 1998). The final degree of hydration $\xi_{\infty}$ is related to the water/cement ratio of the mixture (Byfors 1980; Waller et al. $¥ 996$ ), and it can be estimated as a function of it as, for instanoe (Pantazopfrulo and Mills 1995),

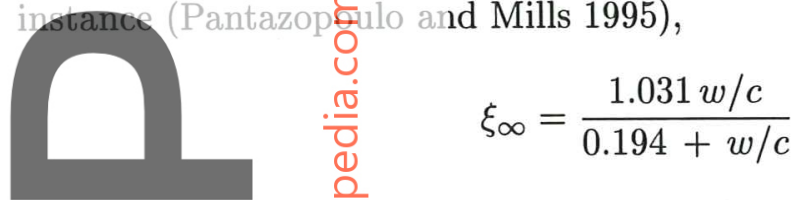

Now, defining $\frac{}{\bar{G}}$ material constants $Q_{\xi}=Q_{\chi} \bar{\chi}_{\infty}, k_{\xi}=k_{\chi} \bar{\chi}_{\infty}^{3}, A_{\xi 0}=$ $A_{\chi 0} \bar{\chi}_{\infty}$ and $\eta_{\xi 0}=\eta_{\infty} \bar{\chi}_{\infty}^{2}$, we can write the thermo-chemical coupling term in Eq. (3) as:

$$
L(T, \xi)=\frac{Q(\xi)}{T_{0}}\left(T-T_{0}\right)
$$

where $Q(\xi)=Q_{\xi} \xi \stackrel{0}{*}$ ecause of the linear assumption in Eq. (4). Note that because of this, the hydration degree can also be defined as $\xi=Q / \bar{Q}_{\infty}$, where $\bar{Q}_{o}$ is the figgal ammount of liberated heat in ideal conditions (Torrenti 1992; de Schu过er and Taerwe 1995; Boumuz and Tenoudji 1996; Acker 1997). 
The chemical term in Eq. (5) can now be rewritten as

$$
H(\xi)=\frac{1}{3} k_{\xi} \xi^{3}+\frac{1}{2}\left(\frac{A_{\xi 0}}{\xi_{\infty}}-k_{\xi} \xi_{\infty}\right) \xi^{2}-A_{\xi 0} \xi
$$

The evolution of the newly defined internal variable reads now:

$$
\begin{aligned}
\dot{\xi} & =\frac{k_{\xi}}{\eta_{\xi 0}}\left(\frac{A_{\xi 0}}{k_{\xi} \xi_{\infty}}+\xi\right)\left(\xi_{\infty}-\xi\right) \exp \left(-\bar{\eta} \frac{\xi}{\xi_{\infty}}\right) \exp \left(-\frac{E_{a}}{R T}\right) \\
& =\widetilde{A}_{\xi}(\xi) \exp \left(-\frac{E_{a}}{R T}\right) \geq 0
\end{aligned}
$$

The function $\widetilde{A}_{\xi}(\xi)=A_{\xi} / \eta_{\xi}$ was introduced in Ulm and Coussy (1996) as a normalized affinity that completely characterizes the macroscopic hydration kinetics for a given concrete mixture. This function can be obtained experimentaly fronan adiabatic calorimetric test, as explained below. The model presented he proposes an analytical expression for this function.

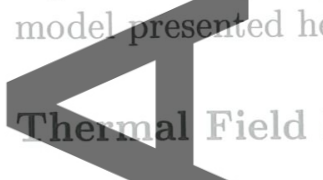

From the first and 3 second principles of thermodynamics the thermal field equation can be ten, in its entropy rate form, as

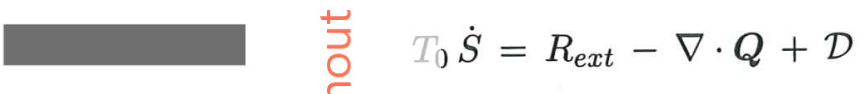

where $R_{\text {ext }}$ are the external volume heat sources, $Q$ is the heat flux and $\mathcal{D}$ is the dissipation (tare, $\mathcal{D}=\mathcal{D}_{\text {chem }}$ ), which is usually considered negligible compared to the $\frac{0}{n}$ ner terms in the equation. Taking the time derivative of the state equation for the entropy, Eq. (6), yields $T_{0} \dot{S}=C \dot{T}-\dot{Q}=$
$C \dot{T}-Q_{\zeta}$
s, so that the thermal field equation can be written in its usual form, as

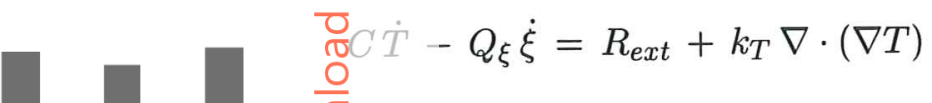

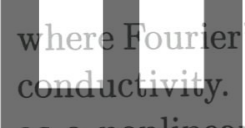

has been used $\left(\boldsymbol{Q}=k_{T} \nabla T\right)$, with $k_{T}$ being the thermal NoteQ hat the term due to the hydration heat, $\dot{Q}$, actually acts egnal heat source. The thermo-chemical model described explicitly allows the determination of this term through Eq. (16).

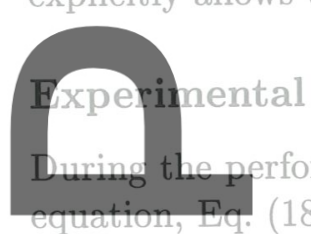

This, together wit

hydration degree

where $T_{0}$ is the i $\mathbb{H}_{\text {tial }}$ temperature, $T^{a d}$ is the measured temperature of concrete along the experiment and $T_{\infty}^{a d}$ is final reached temperature. Also

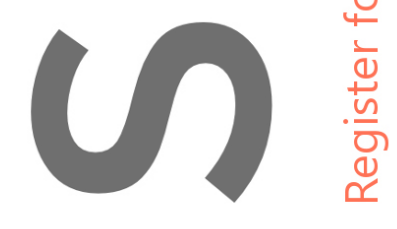


the average value of the constant $Q_{\xi}$ for the experiment can be evaluated as

$$
Q_{\xi}=\frac{C}{\xi_{\infty}}\left(T_{\infty}^{a d}-T_{0}\right)=C\left(\bar{T}_{\infty}^{a d}-T_{0}\right)
$$

where $\bar{T}_{\infty}^{a d}$ is the final reached temperature in ideal conditions (when $\xi_{\infty}=$ 1). Now, using Eqs. (16), (19) and (21), the normalized affinity can be expressed as

$$
\widetilde{A}_{\xi}(\xi)=\frac{\xi_{\infty} \dot{T}^{a d}}{T_{\infty}^{a d}-T_{0}} \exp \left(\frac{E_{a}}{R T^{a d}}\right)
$$

where $\dot{T}^{a d}$ is the measured temperature rate along the experiment. Therefore, it is possible to measure the relationship $\widetilde{A}_{\xi}-\xi$ experimentally. The use of the analytical expression proposed in the present model for this function, Eq. (16), allows the definition of the experimentally obtained function by the calibration of three material properties, $k_{\xi} / \eta_{\xi 0}, A_{\xi 0} / k_{\xi}$ and $\bar{\eta}$, which

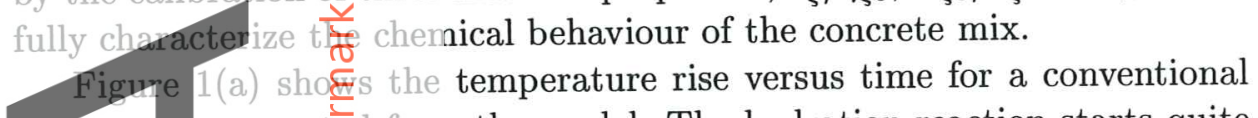
concrete as computed from the model. The hydration reaction starts quite slowly, because of after the so-called as tivation period. Afterwards, the reaction is very fast in adiabatic condition, due to its thermo-activated character. Temperature rises rapidly duringthe first hours, until the hydration degree reaches a value

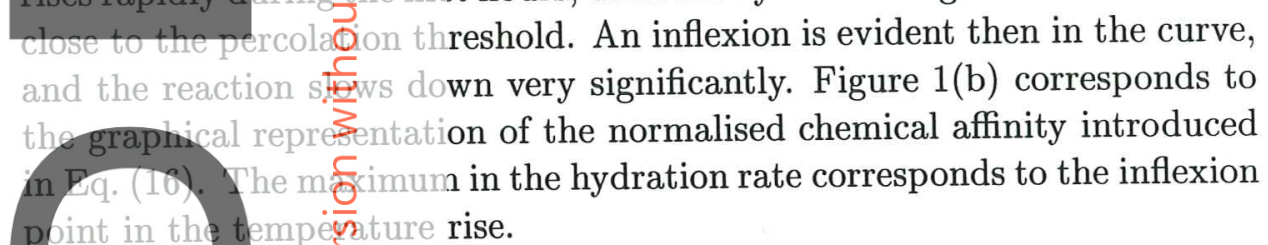
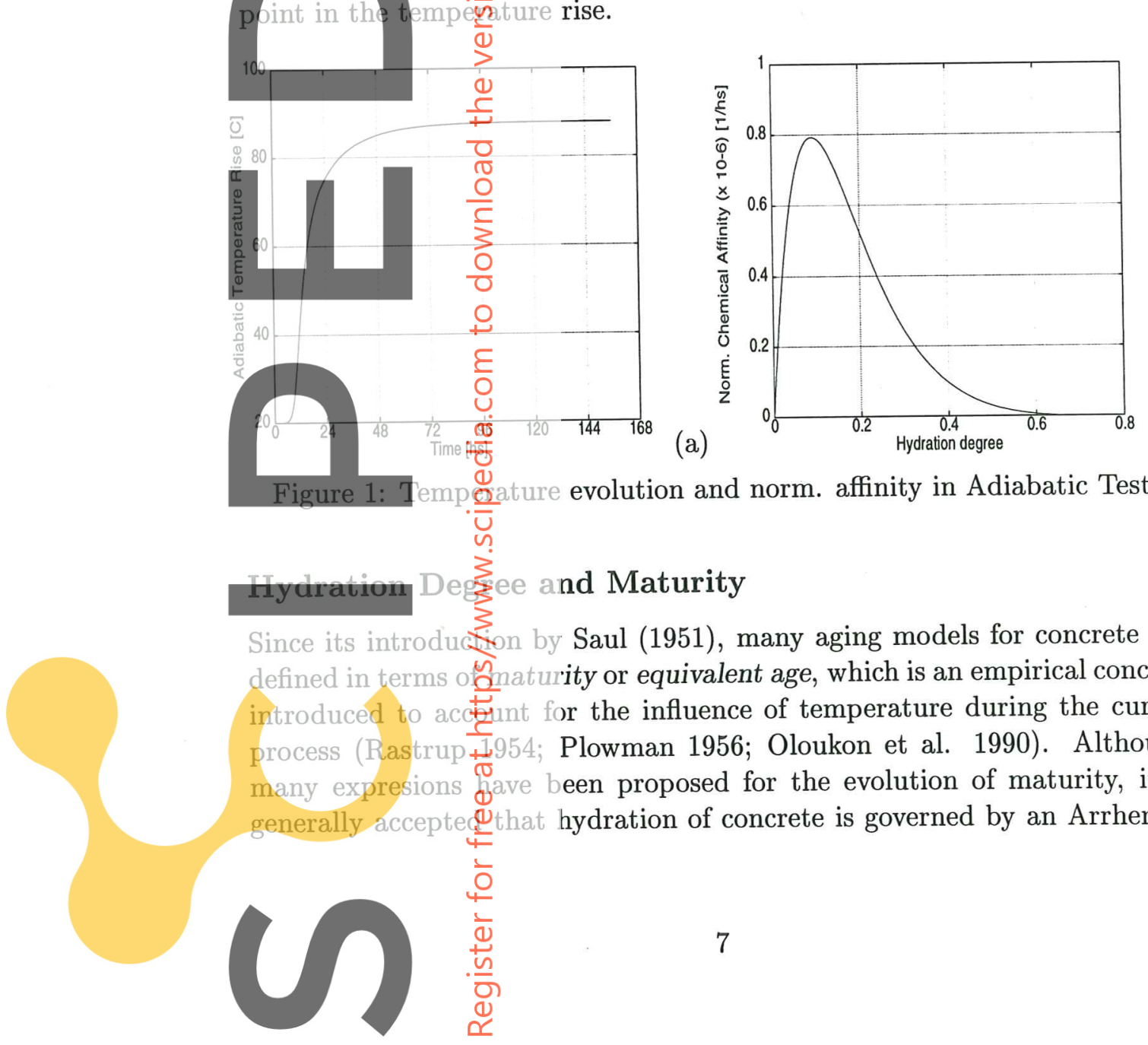

Gature evolution and norm. affinity in Adiabatic Test.

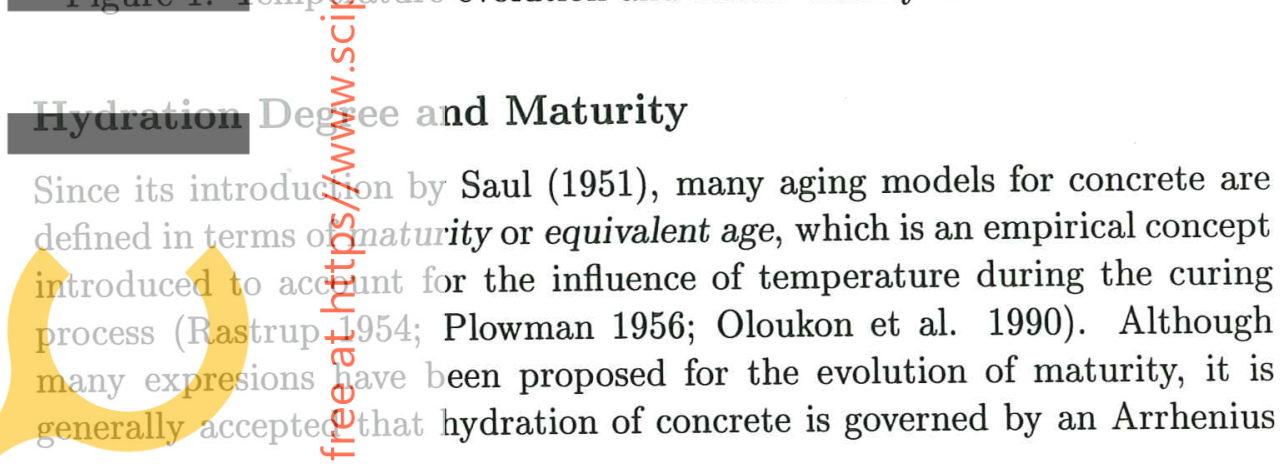


type equation (Copeland et al. 1962; Carino 1981; Hansen and Nielsen 1985; Chengju 1989) which leads to a maturity concept defined as

$$
\mu_{t}(T, t)=\int_{0}^{t} \exp \left[-\frac{E_{a}}{R}\left(\frac{1}{T(\tau)}-\frac{1}{T_{r}}\right)\right] d \tau
$$

where $t$ is the time or, in rate form, as

$$
\dot{\mu}_{t}=\exp \left[-\frac{E_{a}}{R}\left(\frac{1}{T(t)}-\frac{1}{T_{r}}\right)\right]
$$

where $T_{r}$ is the reference temperature for which maturity coincides with real time. From a more fundamental standpoint, it is clear that the concept of maturity has to be related to the concepts of hydration extent and hydration degree. In the present model, comparing Eqs. (16) and (24) yields the relation (Ulm and Coussy 1996)

$$
\frac{\mathbb{E}_{t}}{\Phi_{t}}=\exp \left(-\frac{E_{a}}{R T_{r}}\right) \widetilde{A}_{\xi}(\xi)=c_{r} \widetilde{A}_{\xi}(\xi)
$$

t. This differential equation can be integrated to obtain the retation be
process. This means that, in general, either of the two variables can be used indistinctly $\frac{\tau}{\oplus \pm}$ the definition of the aging models, although the hydration degree contept provides a link with a consistent thermodinamical

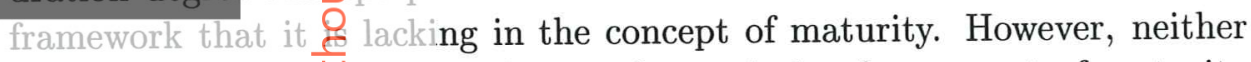
the hydration degity by itself, nor, alternatively, the concept of maturity This is duc to the $\frac{\text { Q }}{\text { gnificant role that temperature has in the development }}$ strength at early ages. This will be discussed in the next Section.

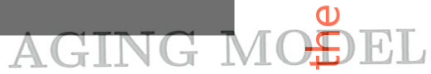

HI

$\underset{\mathscr{C}}{\mathscr{Q}}$ elative proportions and physical properties of the basic $\mathrm{f}$ concete during the chemical reaction of hydration is a pheo aging. From a macroscopic level, aging is observed as Techanical properties of the mortar as a function of the hydration degree. Whe influence of the hydration process is qualitatively the

From a microsరiopic level the hydration of cement consists of (Acker 1988): (a) an initid suspension phase during the first 1-2 hours after the te to the cement, in which gel starts to form around the U exist between the particles, (b) an intermediate setting grains but no forces exist between the parter the mixing, which corresponds to the phase during the 24 hours after the mixing, which corresponds to the them, and the dexlopment of the basic solid skeleton between the grains, and (c) a final ha्adening phase, between 1 to 28 days after the mixing, which correspond of the capillary interstitial pores by the hydrates. Furthermore, when considering the aging of concrete, the microestructutal behaviour of the interphase betwea the cement matrix and the aggregates must also be taken into account 
During the last decades, many aging models have been proposed in which the mechanical properties of young concrete were expressed in terms of the hydration degree, or alternatively, of the maturity (Rastrup 1954; Plowman 1956; Oloukon et al. 1990). The basic assumption for these models is that concretes of the same mix at the same hydration degree (or maturity) have the same strength independently of the hydration kinetics occurred to reach that hydration degree (or maturity).

However, there is experimental evidence that the evolution of the concrete strength depends not only on the degree of hydration, but also on the kinetics of the hydration reaction (Byfors 1980; Voltz et al. 1981; Carino 1981; Chengju 1989; Shi and Day 1993; Bland et al. 1994; Wild et al. 1995; Tan and Gjorv 1996). For instance, Verbeck and Helmuth (1968) found that the strength of companion mortar specimens hydrated at $50^{\circ} \mathrm{C}$ was about $20 \%$ lower that that of specimens hydrated at $5{ }^{\circ} \mathrm{C}$, at a given degree of

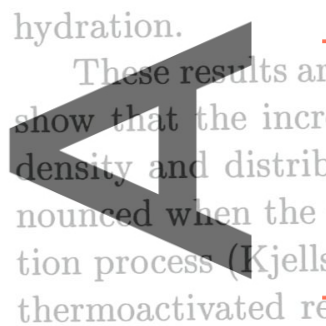

sistent with electronic microscopeo Ition of cement grains. This phenomenon is more promperature rise occurs earlier in the setting and hydraand Detwiler 1993). Being the hydration of cement a skeleton and the higlrates deposit uniformly. On the other hand, curing hich temperature 局creases the rate of hydration. The hydration products for $m$ faster and they deposit close to the unhydrated cement grains. The cess of the free water through the forming solid skeleton is hindered and the void interstitial pores are left (Verbeck and Helmuth 1068). In Kjellsen 890$)$ the formation of a shell around the cement grains \$gher rate of hydration can be observed. The strength of mortar is influenced by the uniformity of the microestructure, and the mechanical proper $\stackrel{0}{0}$ depend on the size and distribution of the interstitial pores between the Orains and the cement paste. Low curing temperatures lead to a uniform ${ }^{-}$stribution of hydration products and interstitial pores. On the contrary, of high curing temperatures the solid skeleton is stronger and more dense, bot the pores left during the hydration process are larger. In these conditions the mechanical properties of the resulting microstructure, such as the stōength and the elastic modulus, are significantly reduced. In view of this the is concluded that concrete strength cannot be related directly to the hyderion degree (or maturity), and therefore, the mechanical properties cannot \&e obtained without the consideration of the hydration kinetics. A realisti aging model must be established in which the mechanical properties actzen internal-like variables, and their evolution laws must be formulate in of at least, hydration degree and temperature.

The aging mo 1 presented here contemplates the evolution of the compressive and tensing uniaxial strengths and the uniaxial elastic modulus during the hydration rocess of the concrete, because these are the basic parameters used in the mechanical damage model described in the companion paper. For simpliqity, Poisson's ratio is assumed to remain constant. The effect of the curing temperature is explicitly included in the model. 


\section{Compressive Strength}

The parameter mostly used in practice for the mechanical characterization of concrete is the compressive strength, $f^{-}$. Other relevant mechanical properties such as the tensile strength, $f^{+}$and the elastic modulus, $E$, are usually estimated as functions of $f^{-}$. Such is certainly the common rule in most codes of practice (ACI 1987; CEB 1990; MOPT 1991). Here, the same procedure will be followed.

It is common practice for aging models to consider the evolution of the compressive strength of concrete as a direct function of the hydration degree, defining an aging function $\lambda_{f}^{-}(\xi)$, in the form

$$
f^{-}(\xi)=\lambda_{f}^{-}(\xi) f_{\infty}^{-}
$$

where $f_{\infty}^{-}$is the final compressive strength and the aging function satisfies the conditions $\lambda_{f}^{-}(\xi) \geq 0$ and $\lambda_{f}^{-}\left(\xi_{\infty}\right)=1$. In rate form, this relation can be written as

$$
\dot{f}^{-}(\xi)=\dot{\lambda}_{f}^{-}(\xi) f_{\infty}^{-}=\lambda_{f, \xi}^{-} \dot{\xi} f_{\infty}^{-}
$$

where $\lambda_{f, \xi}^{-}=d \lambda_{f}^{-} / d \xi$. Linear, bilinear, parabolic and cubic expressions have been proposed in the literature for the aging function (Byfors 1980; Neville 1981; Parrot et al. 1990; Torrenti 1992; Rostassy et al. 1993; de Schutter and Taerwe 1995; Mak and Torri 1995; Ulm and Coussy 1995).

However, as it was explained above, the effect of the curing temperature on the evolution of the compressive strength makes it necessary to relate this evolution to the hydration kinetics. To this end, let us introduce an aging internal variable, $\kappa$, so that Eq. (26) is replaced by

$$
f^{-}(\kappa)=\kappa f_{\infty}^{-} \quad \kappa \geq 0
$$

Note that $\kappa$ can be considered a normalized strength variable. Thus, it will be called here aging degree. It will be shown in the companion paper that the aging degree controls the evolution of the chemical hardening.

The evolution of the aging degree must be related to the hydration kinetics and the temperature. Inspired in Eq. (27) it is here proposed to take

$$
\dot{\kappa}=<\lambda_{T}(T) \lambda_{f, \xi}^{-}(\xi)>\dot{\xi}
$$

For the term $\lambda_{T}$ we propose the expression

$$
\lambda_{T}=\left(\frac{T_{T}-T}{T_{T}-T_{r e f}}\right)^{n_{T}}
$$

where $T_{\text {ref }}$ is the reference temperature for the determination of $f_{\infty}^{-}, T_{T}$ represents the maximum temperature at which hardening of concrete may occur and $n_{T}$ is a material property. Note that for $T \geq T_{r e f}$ it results $\lambda_{T} \leq 1$, thus diminishing the increase of strength; on the contrary, for $T \leq T_{\text {ref }}$ it results $\lambda_{T} \geq 1$, thus enhancing the increase of strength.

For the term $\lambda_{f, \xi}^{-}$we propose the linear expression

$$
\lambda_{f, \xi}^{-}(\xi)=A_{f} \xi+B_{f} \quad \text { for } \quad \xi \geq \xi_{\text {set }}
$$

where $\xi_{\text {set }}$ is a value defining the end of the setting phase, just when the concrete may begin to be considered a solid (Byfors 1980; Boumiz and 
Tenoudji 1996; Acker 1997). Values $\xi_{\text {set }}=0.1$ to 0.4 have been proposed in the literature, depending on the type of cement and the water/cement ratio (Torrenti 1992; de Schutter and Taerwe 1996). A linear relationship with $A_{f}=2 f_{\text {set }}^{-} /\left(f_{\infty}^{-} \xi_{\text {set }}^{2}\right)$ and $B_{f}=0$ may be considered for $\xi \leq \xi_{\text {set }}$.

Substituting Eq. (16) into Eq. (29) we have

$$
\dot{\kappa}=<\lambda_{T}(T) \lambda_{f, \xi}^{-}(\xi)>\widetilde{A}_{\xi}(\xi) \exp \left(-\frac{E_{a}}{R T}\right)
$$

which clearly expresses the dependency of the aging variable both on the hydration degree and on temperature.

It should be noted that the present approach corresponds to the physical observation that two concrete samples with identical mixing but cured at different temperatures show different strengths for the same hydration degree. In Kjellsen and Detwiler (1993) the activation energy of the reaction was considered a function of the temperature and the hydration degree to introduce what they called the effect of "retardation" due to high curing temperature. Even if good matches are obtained in terms of curves showing strength increase versus time, this alternative approach is incorrect from the physical standpoint, as this will not only affect the evolution of strength but also the hydration kinetics in an unrealistic manner.

\section{Tensile Strength and Elastic Moduli}

The final tensile strength is usually considered to be related to the final compressive strength. Most codes of practice (ACI 1987; CEB 1990; MOPT 1991) recommend for this relation the expression $f_{\infty}^{+}=A_{+}\left(f_{\infty}^{-}\right)^{2 / 3}$, where $A_{+}$is a constant. If this relationship holds for the whole aging process, and considering Eq. (28), it follows that (Rostassy et al. 1993)

$$
f^{+}(\kappa)=\lambda_{f}^{+}(\kappa) f_{\infty}^{+}=\kappa^{2 / 3} f_{\infty}^{+}
$$

The final elastic modulus is also often considered a function of the final compressive strength (CEB 1990; MOPT 1991), a usual dependency being of the form $E_{\infty}=A_{E}\left(f_{\infty}^{-}\right)^{1 / 2}$, where $A_{E}$ is a constant. If this dependency holds for the whole aging process, and considering Eq. (28), we can write

$$
E(\kappa)=\lambda_{E}(\kappa) E_{\infty}=\kappa^{1 / 2} E_{\infty}
$$

With the above relationships and the hypothesis of constant Poisson's ratio the bulk and shear moduli can be written as

$$
K(\kappa)=\lambda_{E}(\kappa) K_{\infty} \quad \text { and } \quad G(\kappa)=\lambda_{E}(\kappa) G_{\infty}
$$

with the usual expressions $K_{\infty}=E_{\infty} / 3(1-2 \nu)$ and $G_{\infty}=E_{\infty} / 2(1+\nu)$.

The functional dependencies expressed by Eqs. (33) and (34) need to be experimentally confirmed. In de Schutter and Taerwe (1996) it was reported that the tensile strength develops faster than the compressive strength, but slower than the elastic modulus. In de Schutter and Taerwe (1997) threepoint bending tests were performed on unnotched prisms at different concrete ages, ranging from 24 hours to 28 days, in order to study the evolution of the softening behaviour during hardening. The experimentally found exponent for the tensile strength varied between 0.46 and 0.88 , with an average 
value of 0.70 . These results are consistent with the present proposal of a $2 / 3$ exponent.

Figure 2(a) shows the evolution of the strength in terms of the hydration degree at different curing temperatures $\left(T_{\text {ref }}, T_{\text {ref }}+20{ }^{\circ} \mathrm{C}, T_{\text {ref }}+40^{\circ} \mathrm{C}\right)$. Note how an increase of the curing temperature leads to a significant decrease in the attained final compressive strength. This is important in massive concrete structures, where most of the concrete hardens in quasiadiabatic conditions, with important temperature rises above the placing temperature. Figure 2(b) shows curves of relative evolution of the normalized compressive strength, tensile strength and elastic modulus in terms of the aging degree.

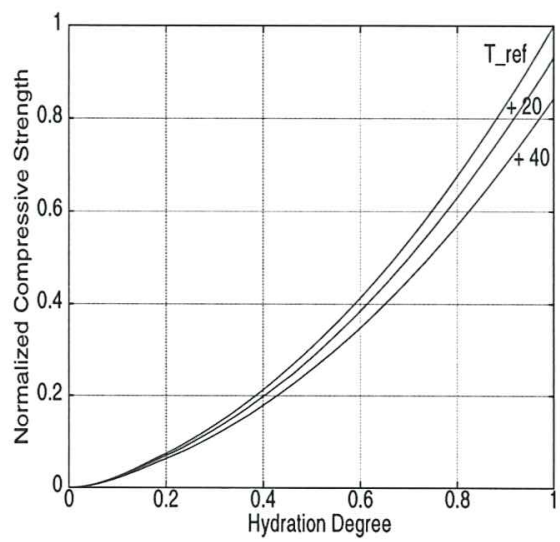

(a)

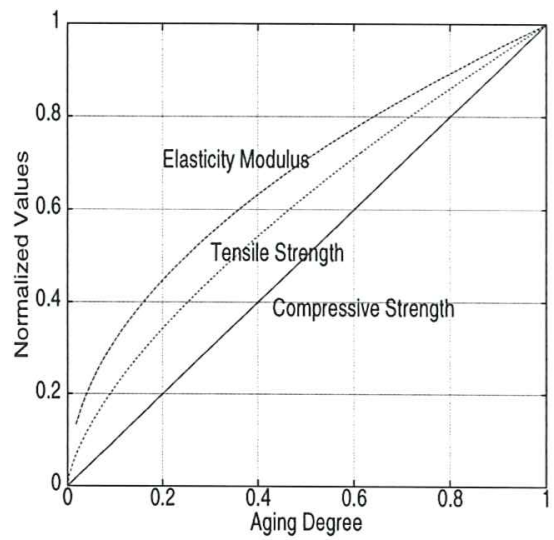

(b)

Figure 2: (a) Strength evolution at different temperatures; (b) Relative mechanical aging.

\section{Tensile and Compressive Fracture Energies}

The stored elastic energy per unit volume is proportional to the square of the stress and inversally proportional to the elastic moduli of the material. The energies released per unit area when damage or fracture (under tension or compression) occurs are considered material properties called the tensile and compressive fracture energies, $G_{f}^{+}$and $G_{f}^{-}$, respectively. These material properties increase as the hydration of concrete progresses, and therefore, they depend on the aging degree:

$$
G_{f}^{+}(\kappa)=\lambda_{G}^{+}(\kappa) G_{f \infty}^{+} \quad \text { and } \quad G_{f}^{-}(\kappa)=\lambda_{G}^{-}(\kappa) G_{f \infty}^{-}
$$

Here, we will assume that the fracture energies are proportional to the maximum stored elastic energy per unit volume, thus establishing the dependence of the fracture energies on the aging degree as

$$
\begin{aligned}
& \lambda_{G}^{+}(\kappa)=\frac{\lambda_{f}^{+}(\kappa)^{2}}{\lambda_{E}(\kappa)}=\kappa^{5 / 6} \\
& \lambda_{G}^{-}(\kappa)=\frac{\lambda_{f}^{-}(\kappa)^{2}}{\lambda_{E}(\kappa)}=\kappa^{3 / 2}
\end{aligned}
$$

These functional dependencies also need to be experimentally confirmed. The experimentally found exponent for the tensile fracture energy in de Schutter and Taerwe (1997) varied between 0.46 and 1.10, with an average value of 0.87 . These results are consistent with the present proposal of a 5/6 exponent. 


\section{NUMERICAL SIMULATIONS}

This Section presents an assessment of the thermo-chemical model described above. All the problems presented are solved advancing step-by-step in time. For each time step, the thermal equation, Eq. (18) is solved, together with the differential equation governing the chemical process, Eq. (16) (Prato et al. 1997).

\section{Hydration model}

This Subsection is devoted to compare available experimental data with numerical predictions obtained using the thermo-chemical model proposed above. Therefore, all the tests in this Subsection were conducted in adiabatic conditions.

Bentz et al. (1998) conducted a series of experimental adiabatic tests to measure the temperature rise observed during the curing of conventional and high-performance concretes. We have selected here the results reported for conventional concretes with $w / c=0.35$ and $w / c=0.45$, as well as for high-performance concrete with $w / c=0.45$ and silica fume-to-cement mass ratio $s / c=0.20$. The material properties used for the numerical simulation are listed in Table 1 . Note that only the chemical related properties are necessary. The values used for the final degree of hydration, $\xi_{\infty}$, are those given by Eq. (13).

Figure 3 shows the comparison between the experiments and the results obtained using the proposed thermo-chemical model. The dots represent the experimental values; the solid line represents the prediction by the model. Figures 3(a) and 3(c) show the temperature rise versus time for both conventional concrete mixes, respectively.

The hydration reaction starts quite slowly, because of its very low initial chemical affinity. However, it accelerates after the first 2-3 hours, the socalled activation period. Afterwards, the reaction is very fast in adiabatic conditions, due to its thermo-activated character. Temperature rises rapidly during the first 12 hours, until the hydration degree reaches a value close to $\xi_{\text {set }}=0.2$, which can be considered the percolation threshold. An inflexion is evident then in the curves, and the reaction slows down very significantly.

\begin{tabular}{|c|c|c|c|}
\hline Properties & Bentz et al. (I) & Bentz et al. (II) & Bentz et al. (III) \\
\hline \hline$w / c$ & 0.35 & 0.45 & 0.45 \\
$s / c$ & 0.0 & 0.0 & 0.20 \\
\hline$C\left[\mathrm{~J} / \mathrm{m}^{3}{ }^{\circ} \mathrm{C}\right]$ & $2.33 \times 10^{6}$ & $2.33 \times 10^{6}$ & $2.33 \times 10^{6}$ \\
$k_{T}\left[\mathrm{~J} / \mathrm{m} h s^{\circ} \mathrm{C}\right]$ & 5400 & 5400 & 5400 \\
$T_{0}\left[{ }^{\circ} \mathrm{C}\right]$ & 21 & 21 & 21 \\
\hline$\xi_{\infty}$ & 0.66 & 0.72 & 0.72 \\
$k_{\xi} / \eta_{\xi 0}[1 / h s]$ & $0.35 \times 10^{8}$ & $0.28 \times 10^{8}$ & $0.15 \times 10^{8}$ \\
$\bar{\eta}$ & 6 & 5.3 & 4.0 \\
$A_{\xi 0} / k_{\xi}$ & $1.0 \times 10^{-5}$ & $5.0 \times 10^{-4}$ & $5.0 \times 10^{-4}$ \\
$E_{a} / R\left[{ }^{\circ} K\right]$ & 5000 & 5000 & 5000 \\
$Q_{\xi}\left[\mathrm{J} / \mathrm{m}^{3}\right]$ & $2.39 \times 10^{8}$ & $2.02 \times 10^{8}$ & $1.73 \times 10^{8}$ \\
\hline
\end{tabular}

Table 1: Material Properties for Hydration Numerical Simulations. 


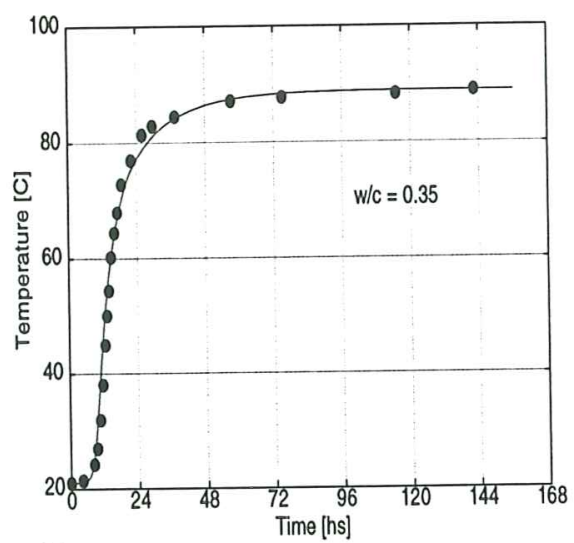

(a)

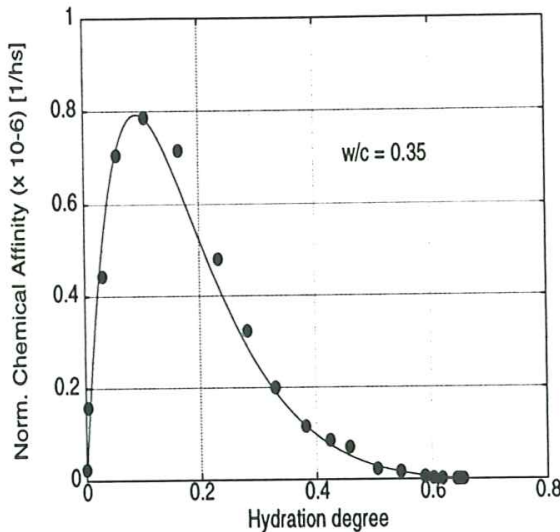

(b)
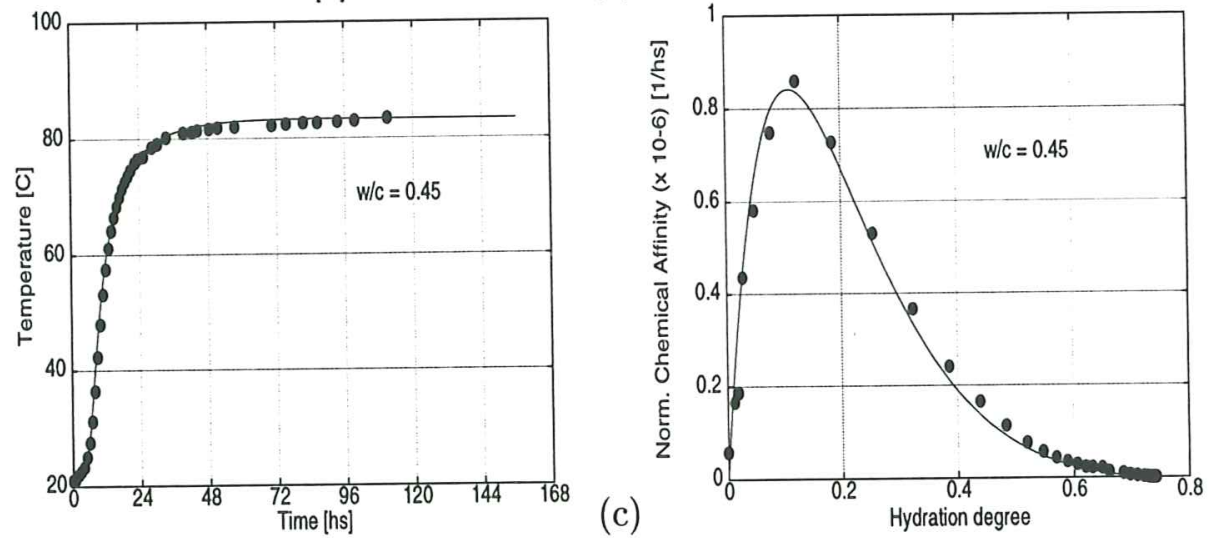

(d)

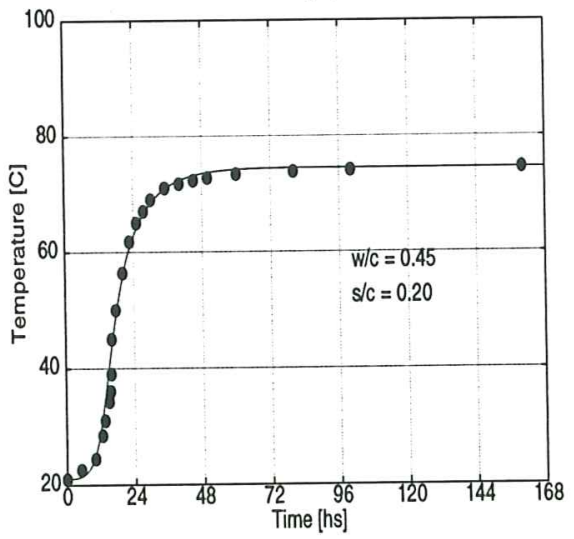

(c)

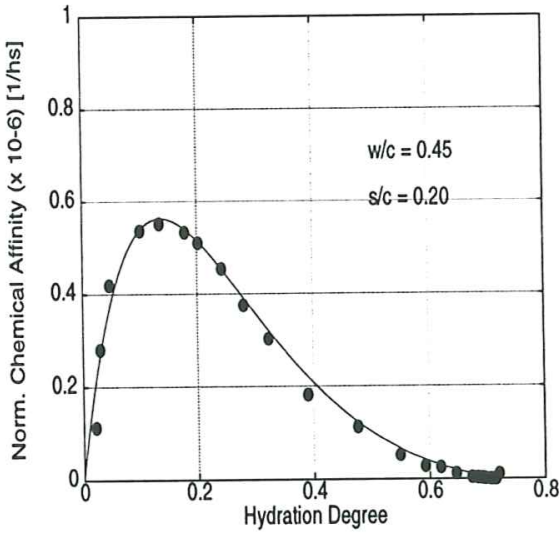

Figure 3: Temperature evolution and norm. affinity for Adiabatic Tests.

The process is practically completed after 6 days in figure 3(a) and 5 days in figure 3(c). Note that the overall behaviour is very well captured, and that the deviations between the model predictions and the experimental measurements are minimal.

Figures 3(b) and 3(d) show a graphical representation of the normalised chemical affinity introduced in Eq. (16). The experimental values have been obtained from the corresponding temperature versus time measured curves using the procedure described by Eq. (22). The above described stages during the hydration process are also quite evident in these two figures. The maxima in the hydration rate correspond to the inflexion point in the temperature rise.

Figures 3(e) and 3(f) show results corresponding to the high performance concrete with silica fume addition. Note that the proposed model is also 
able to match adequately the experimental behaviour of this type of concrete mixes. This means that the pozzolanic reaction between calcium hydroxide $(\mathrm{CH})$ and silica fume $(S)$ does not differ too much from the other chemical reactions that take place during the hydration of conventional Portland cement concretes. This is a fortunate and useful verification of the possibilities of the model. However, this does not mean that the present model can be used for other types of concrete mixes without careful consideration. For instance, the experimental evidence shows that concretes made with blast furnace slag cement exhibit a different heat production rate than that of conventional Portland cement (de Schutter and Taerwe 1995). These specific features are not contemplated in the present model.

\section{Aging model}

This Subsection is devoted to compare available experimental data with numerical predictions obtained using the aging model proposed above. The experimental sets selected focus on the influence of the curing temperature in the evolution of the compressive strength. Therefore, all the tests in this Subsection were conducted in isothermal conditions.

\section{Kjellsen's Tests}

The first set consists of tests conducted by Kjellsen (1990), and also reported in Kjellsen and Detwiler (1993). They refer to $w / c=0.5$ mortar, the cement used being ASTM Type I/III. The material properties used for the numerical simulation are listed in Table 2 . Note that only the chemical and aging related properties are necessary. The value used for the final degree of hydration, $\xi_{\infty}$, is estimated using Eq. (13).

\begin{tabular}{|c|c|c|c|}
\hline Properties & Kjellsen & Carino & Wild et al \\
\hline \hline$w / c$ & 0.5 & 0.43 & 0.5 \\
\hline$C\left[\mathrm{~J} / \mathrm{m}^{3}{ }^{o} \mathrm{C}\right]$ & $2.07 \times 10^{6}$ & $2.07 \times 10^{6}$ & $2.07 \times 10^{6}$ \\
$k_{T}\left[\mathrm{~J} / \mathrm{m} h s^{\circ} \mathrm{C}\right]$ & 5400 & 5400 & 5400 \\
$T_{0}\left[{ }^{\circ} \mathrm{C}\right]$ & 21 & 21 & 21 \\
\hline$\xi_{\infty}$ & 0.75 & 0.71 & 0.75 \\
$k_{\xi} / \eta_{\xi 0}[1 / h s]$ & $0.32 \times 10^{8}$ & $0.3 \times 10^{8}$ & $0.2 \times 10^{5}$ \\
$\bar{\eta}$ & 6.5 & 6 & 6 \\
$A_{\xi 0} / k_{\xi}$ & $1.0 \times 10^{-5}$ & $1.0 \times 10^{-4}$ & $1.0 \times 10^{-4}$ \\
$E_{a} / R\left[{ }^{\circ} \mathrm{K}\right]$ & 5000 & 5000 & 3000 \\
$Q_{\xi}\left[\mathrm{J} / \mathrm{m}^{3}\right]$ & $1.25 \times 10^{8}$ & $1.25 \times 10^{8}$ & $1.25 \times 10^{8}$ \\
\hline$\xi_{\text {set }}$ & 0.2 & 0.2 & 0.2 \\
$A_{f}$ & 0.47 & 1.98 & 0.87 \\
$B_{f}$ & 0.66 & 0.43 & 0.15 \\
$f_{\infty}^{-}[\mathrm{MPa}]$ & 58 & 59 & 88.0 \\
$T_{T}\left[{ }^{\circ} \mathrm{C}\right]$ & 100 & 100 & 100 \\
$T_{r e f}\left[{ }^{\circ} \mathrm{C}\right]$ & 20 & 23 & 20 \\
$n_{T}$ & 0.4 & 0.4 & 0.25 \\
\hline
\end{tabular}

Table 2: Material Properties for Aging Numerical Simulations. 

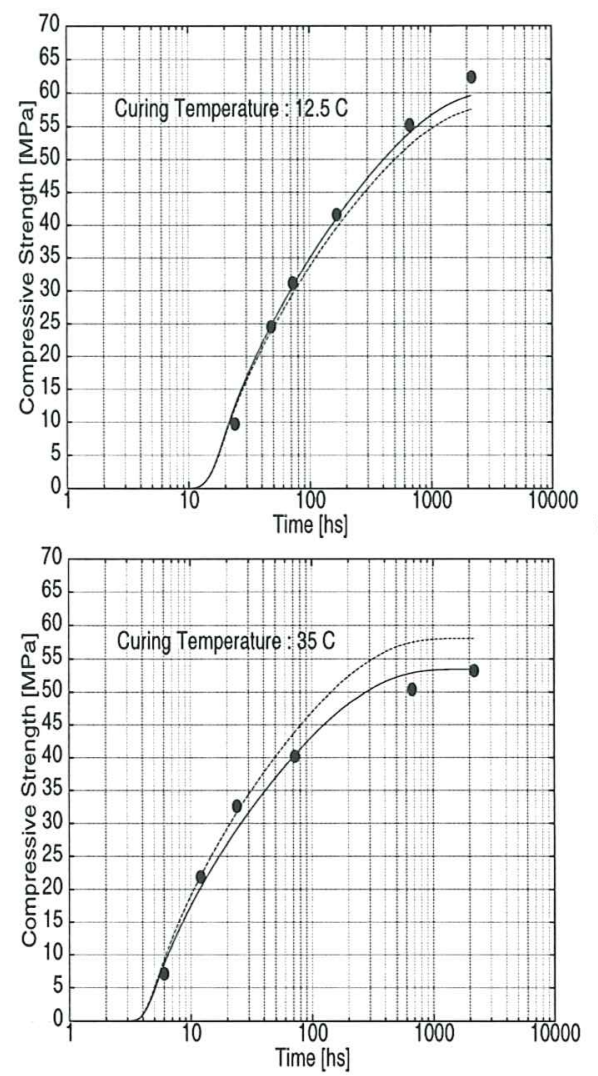

(a)

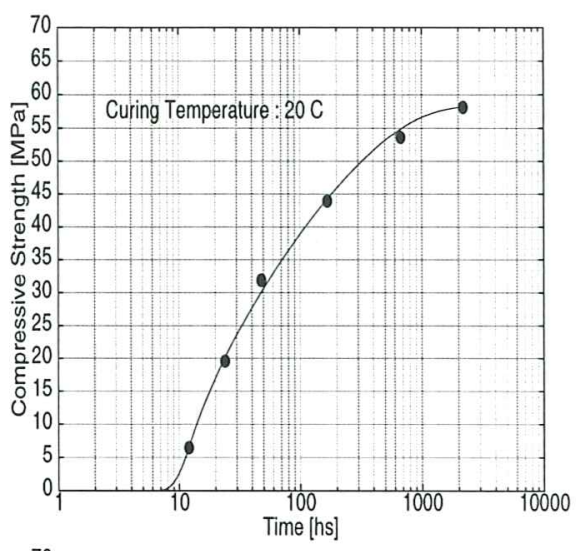

(b)

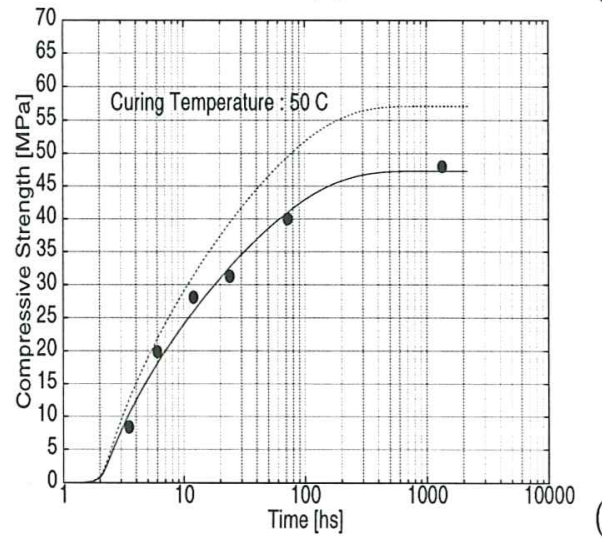

(d)

Figure 4: Strength evolution for Kjellsen's Tests.

Figure 4 shows the compressive strength versus time curves obtained for the curing temperatures $T_{0}=12.5,20,35$ and $50^{\circ} \mathrm{C}$, respectively. The dots represent the experimental values, the solid line is the prediction by the model, and the dashed line is the result obtained neglecting the influence of the temperature in the evolution of the aging function, that is, taking $\lambda_{T}=1$ in Eq. (29).

The effect of the curing temperature is twofold: (a) the thermoactivated character of the hydration reaction is well evident in these plots, as the process of hardening is accelerated by the increase in curing temperature; and (b) the significant loss of strength with increasing curing temperature is clear. The first effect is particularly evident at the initiation of the hydration process, with the activation phase being shortened as the curing temperaure is increased. The second effect makes, for instance, that mortar cured at $50{ }^{\circ} \mathrm{C}$ shows a loss of attainable strength of $23 \%$, compared to the one cured at $12.5^{\circ} \mathrm{C}$. Therefore, the necessity of accounting for the effect of the temperature in a realistic chemo-aging model is demonstrated, particularly for higher curing temperatures.

The overall agreement between experimental and numerical results is very good. Both significant effects of the curing temperature in the evolution of the strength are well captured with the present model. Note that the proposed model allows for remarkably good predictions for curing temperatures below and above the reference temperature, $T_{\text {ref }}$. 

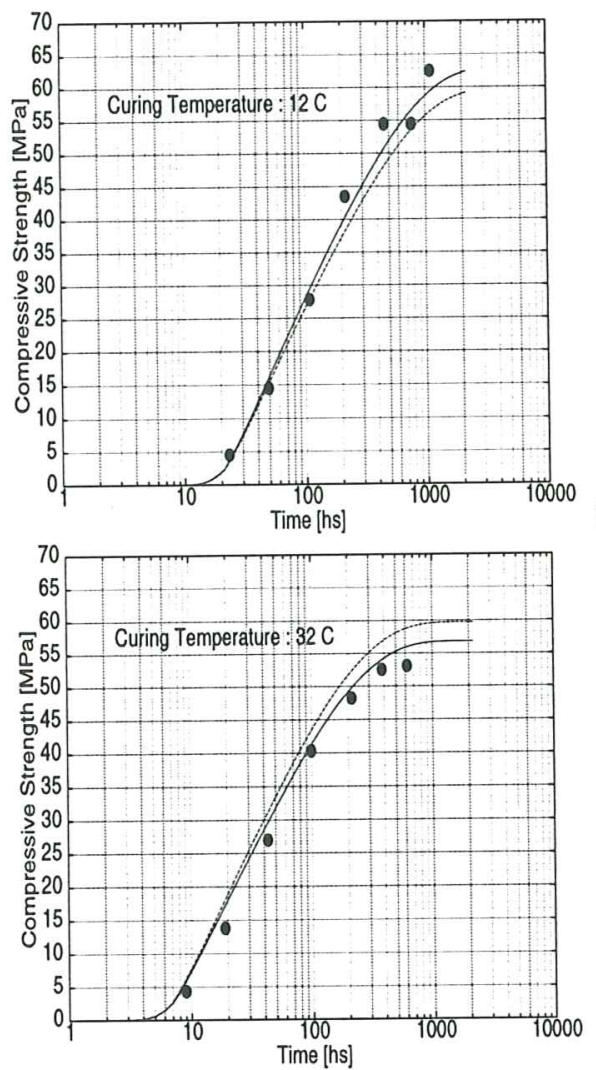

(a)

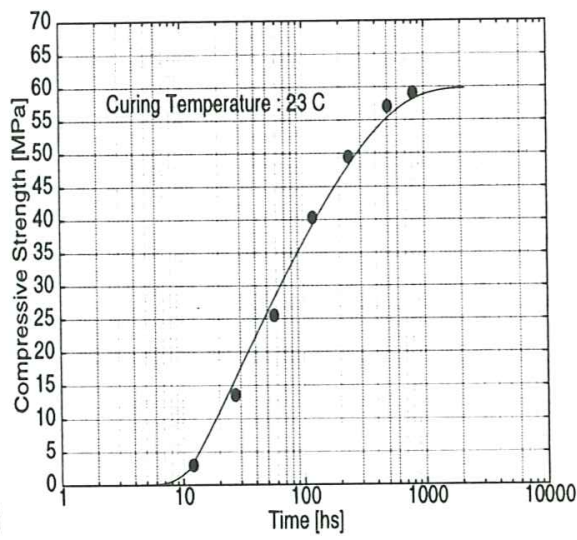

(b)

(c)

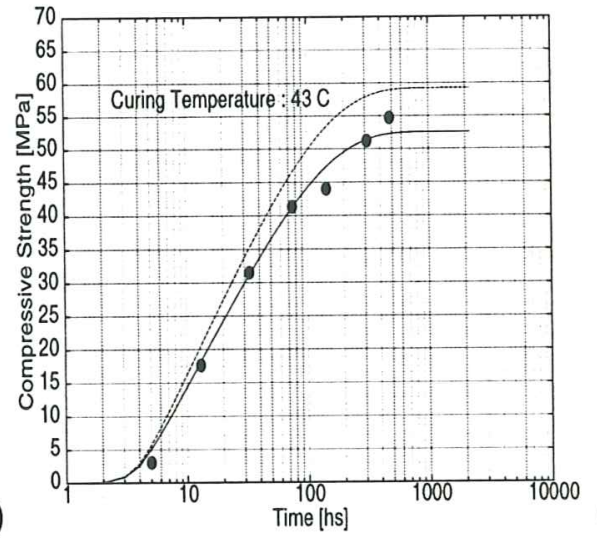

Figure 5: Strength evolution for Carino's Tests.

\section{Carino's Tests}

The second set consists of tests conducted by Carino (1981), and also reported in Kjellsen and Detwiler (1993). They refer to $w / c=0.43$ mortar, the cement used being ASTM Type I. The material properties used for the numerical simulation are listed in Table 2.

Figure 5 shows the compressive strength versus time curves obtained for the curing temperatures $T_{0}=12,23,32$ and $43^{\circ} \mathrm{C}$, respectively. The dots represent the experimental values, the solid line is the prediction by the model, and the dashed line is the result obtained neglecting the influence of the temperature in the evolution of the aging function. Note that mortar cured at $43{ }^{\circ} \mathrm{C}$ shows a loss of attainable strength of $13 \%$, compared to the one cured at $12{ }^{\circ} \mathrm{C}$. The agreement between numerical and experimental results is very good for all the cases considered, both for curing temperatures below and above the reference temperature, $T_{\text {ref }}$.

\section{Wild et al. Tests}

The third set consists of tests conducted by Wild et al. (1995) to investigate the factors influencing the strength development of concrete containing silica fume. The results used here refer to Ordinary Portland Concrete. The mix was designed according to the US Department of Enviroment specifications with the aim of producing high strength concrete $(70 \mathrm{MPa})$. The material properties used for the numerical simulation are listed in Table 2.

Figure 6 shows the compressive strength versus time curves obtained for the curing temperatures $T_{0}=20$ and $50^{\circ} \mathrm{C}$, respectively. The dots represent 
the experimental values, the solid line is the prediction by the model, and the dashed line is the result obtained neglecting the influence of the temperature in the evolution of the aging function. Note that concrete cured at $50{ }^{\circ} \mathrm{C}$ shows a loss of attainable strength of $6 \%$, compared to the one cured at $20^{\circ} \mathrm{C}$, which is significantly less than the percentage measured for mortars in Sets I and II. The overall agreement obtained between numerical and experimental results is good.

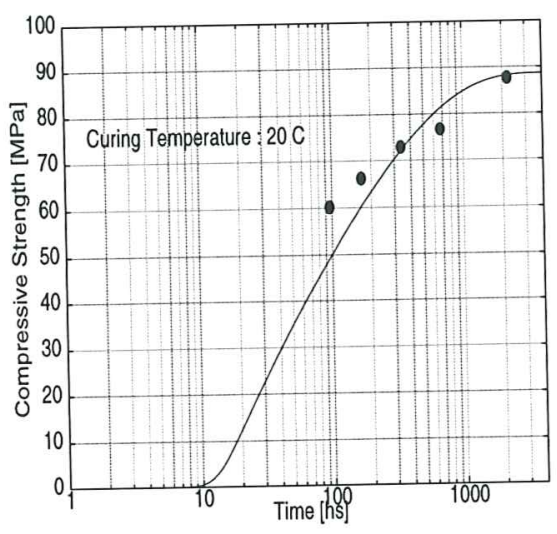

(a)

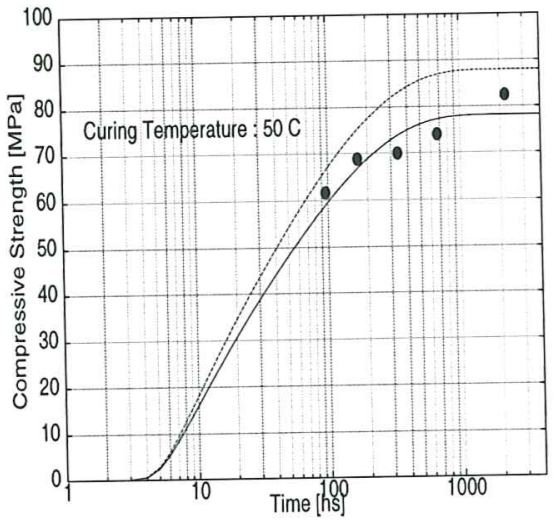

Figure 6: Strength evolution for Wild at al. Tests.

\section{CONCLUSION}

This paper describes a thermo-chemo-mechanical model that accounts for many of the features observed in the behaviour of concrete at early ages. A consistent thermodynamic framework is provided for these irreversible processes. Expressions for the free energy are provided from which the state equations are derived. Positive dissipation is guaranteed in all situations. The hydration model is based on the Reactive Porous Media Theory on its thermo-chemical part. A novel aging model is introduced which accounts for the effect of the curing temperature in the evolution of the relevant mechanical properties. The aging degree is introduced as an internal variable, different from the commonly used hydration degree or maturity concepts. The model is well suited for its implementation in a finite element devised for thermal analysis. The capabilities and potentiality of the model are shown by performing numerical simulations of adiabatic and isothermal tests in concrete samples. The qualitative and quantitative agreement between the model results and the available experimental data is remarkably good in all situations.

\section{APPENDIX I. REFERENCES}

ACI (1987). ACI Manual of Concrete Practice, chapter Mass Concrete. ACI 207.1R-87. American Concrete Institute.

Acker, P. (1988). Comportement mecanique du beton: apports de l'aproche physico-chimique (in French). Raport de recherche N. 152, Laboratoire Ponts et Chaussées, Paris, France. 
Acker, P. (1997). Dispositif d'étude de la cinétique d'hydratation des bétons par calimétrie isotherme (in french). Bull. liaison Laboratoire Ponts et Chaussées, Paris, France, N. 210:31-40.

Bentz, D. P., Waller, V., and de Larrard, F. (1998). Prediction of adiabatic temperature rise in conventional and high-performance concrets using a 3-d microstructural model. Cement and Concrete Research, 28(2):285297.

Bland, C., Poole, A., and Patel, H. (1994). The microstructure of concrete cured at elevated temperatures. Institute of Materials Conference on Cement and Concrete Science, 26-27th, St Annes' College, Oxford.

Boumiz, A., Vernet, C., and Tenoudji, F. C. (1996). Mechanical properties of cement pastes and mortars at early ages. Advn. Cem. Bas. Mat., $3: 94-106$.

Byfors, J. (1980). Plain concret at early ages. Technical Report No. fo 3/P16, Swedish Cement and Concrete Research Institute, Stockholm.

Carino, N. J. (1981). Temperature effects on the strength-maturity relation of mortar. Technical Report No. NBSSIR 81-2244, National Bureau of Standards, Washington, D.C.

CEB (1990). CEB-FIP Model Code 1990. Comité Euro-International du Beton.

Chengju, G. (1989). Maturity of concrete method for predicting early-stage strength. ACI Materials Journal, 86(4):341-353.

Copeland, L. E., Kantro, D. L., and Verbeck, G. (1962). Chemistry of hydration of cement. In National Bureau of Standards, W., editor, Proc. 4th Int. Symp. on the Chemistry of Cement, volume Monograph 43, pages 429-465.

Coussy, O. (1995). Mechanics of porous media. John Wiley \& Sons, Chichester, England.

de Schutter, G. and Taerwe, L. (1995). General hydration model for portland cement and blast furnace slag cement. Cement and Concrete Research, 25(3):593-604.

de Schutter, G. and Taerwe, L. (1996). Degree of hydration based description of mehanical properties of early age concrete. Materials and Structures, 29:335-344.

de Schutter, G. and Taerwe, L. (1997). Fracture energy of concrete at early ages. Materials and Structures, 30:67-71.

Hansen, P. F. and Nielsen, A. (1985). Method for quick calculation of temperature differences in concrete members. VTT Symposium 61, Espoo. 
Kjellsen, K. O. (1990). Physical and Mathematical Modelling of Hydration and Hardening of Portland Cement Concrete as a Function of Time and Curing Temperature. PhD thesis, Division of Building Material, Norwegian Institute of Technology.

Kjellsen, K. O. (1996). Heat curing and post-heat curing regimes of highperformance concrete: Influence on microstructure and c-s-h composition. Cement and Concrete Research, 26(2):295-307.

Kjellsen, K. O. and Detwiler, R. J. (1993). Later-age strength prediction by a modified maturity model. ACI Materials Journal, 90(3):220-227.

Mak, S. L. and Torri, K. (1995). Strength development of high strength concretes with and without silica fume uder the influence of high hydration temperatures. Cement and Concrete Research, 25(8):1791-1802.

MOPT (1991). Instrucción para el Proyecto y la Ejecución de Obras de Hormigón en Masa o Armado (in Spanish). MOPT.

Neville, A. M. (1981). Properties of Concrete. John Wiley \& Sons, New York.

Oloukon, F. A., Bourdette, E. G., and Deatherage, J. H. (1990). Early-age concrete strength prediction by maturity - another look. ACI Materials Journal, 87(6):565-572.

Pantazopoulo, S. J. and Mills, R. H. (1995). Microstructural aspects of the mechanical response of plain concrete. ACI Materials Journal, 92(6):605-616.

Parrot, L., Geiker, M., Gutteridge, W., and Killoh, D. (1990). Monitoring portland cement hydration: Comparison of methods. Cement and Concrete Research, 20(6):919-926.

Plowman, J. M. (1956). Maturity and strength of concrete. Magazine of Concrete Research, 8(22):13-22.

Prato, T., Cervera, M., and Oliver, J. (1997). Simulación Numérica del Proceso de Hidratación del Hormigón (in Spanish). Publicación CIMNE N. 14.

Rastrup, E. (1954). Heat of hydration in concrete. Magazine of Concrete Research, 6(17):2-13.

Reinhardt, H. W., Blaauwendraad, J., and Jongedijk, J. (1982). Temperature development in concrete structures taking account of state dependent properties. In Proc. Int. Conf. of Concrete at Early Ages.

Rostassy, F. S., Gustsch, A., and Laube, M. (1993). Creep and relaxation of concrete at early ages - experiments and mathematical modelling. In Mang, H., Bicanic, N., and de Borst, R., editors, Proc. 5th. Int. RILEM Symp. on Creep and Shrinkage of Concrete, pages 453-458. E \& FN Spon.

Saul, A. G. A. (1951). Principles underlying the steam curing of concrete at atmospheric pressure. Magazine of Concrete Research, 2(6):127-140. 
Shi, C. and Day, R. L. (1993). Acceleration of strength gain of limepozzolan cements by thermal activation. Cement and Concrete Research, 23(4):824-832.

Tan, K. and Gjorv, O. E. (1996). Performance of concrete under different curing conditions. Cement and Concrete Research, 26(3):355-361.

Torrenti, J. M. (1992). La résistance du béton au trés jeune age (in french). Bull. liaison Laboratoire Ponts et Chaussées, Paris, France, N. 179:3141.

Torrenti, J. M., Ghenot, I., Laplante, P., Acker, P., and Larrand, F. (1994). Numerical simulation of temperatures ans stresses in concrete at early ages. In Bazant, Z. P. and Carol, I., editors, Proc. Int. Conf. on Computational Modelling of Concrete Structures, pages 559-568. Pineridge Press, Swansea, Wales.

Ulm, F. J. and Coussy, O. (1995). Modeling of thermochemomechanical couplings of concrete at early ages. J. Engrg. Mech., ASCE, 121(7):785794 .

Ulm, F. J. and Coussy, O. (1996). Strength growth as chemo-plastic hardening in early age concrete. J. Engrg. Mech., ASCE, 122(12):1123-1132.

van Breugel, K. (1992a). Hysmostruc: A computer based simulation model for hydration and formation of structure in cement based materials. In Nonat, A. and Mutin, J. C., editors, Hydration and Setting of Cements. RILEM, London.

van Breugel, K. (1992b). Numerical simulation and microstructural development in hardening cement-based materials. Heron, 37(3):1-61.

Verbeck, G. J. and Helmuth, R. H. (1968). Structures and physical properties of cement paste. Proceedings of the Fifth International Symposium on the Chemistry of Cement, Tokyo, pages 1-32.

Voltz, C. K., Tucker, R. L., Burns, N. H., and Lew, H. S. (1981). Maturity effects on concrete strength. Cement and Concrete Research, 11(1):4150 .

Walker, S. and Blem, D. L. (1958). Variations in portland cement. In Proc. ASTM, 58, pages 1009-1032.

Waller, V., de Larrard, F., and Roussel, P. (1996). Utilization of highstrength/high-performance concrete. In RILEM, editor, 4th Int. Symp. RILEM, pages 415-421.

Wild, S., Sabir, B. B., and Khatib, J. M. (1995). Factor influencing strength development of concrete containing silica fume. Cement and Concrete Research, 25(7):1567-1580. 


\section{APPENDIX II. NOTATION}

The following symbols are used in this paper:

$$
\begin{aligned}
& A_{f}, B_{f}=\text { Material properties for aging evolution; } \\
& A_{\chi}, A_{\chi 0}=\text { Chemical affinity, Initial chemical affinity (ref. to } \chi \text { ); } \\
& A_{\xi}, A_{\xi 0}=\text { Chemical affinity, Initial chemical affinity (ref. to } \xi \text { ); } \\
& \widetilde{A}_{\xi} \quad=\text { Normalized chemical affinity; } \\
& C=\text { Heat capacity per unit volume; } \\
& \mathcal{D}, \mathcal{D}_{\text {chem }}=\text { Dissipation, Chemical dissipation; } \\
& E, E_{\infty} \quad=\text { Elastic modulus, Final elastic modulus; } \\
& E_{a}=\text { Activation energy; } \\
& f^{ \pm}, f_{\infty}^{ \pm}=\text {Tensile/compressive strength, Final values; } \\
& f_{\text {set }}^{-}=\text {Compressive strength at setting; } \\
& f_{e}^{ \pm}=\text {Elastic limit in uniaxial tests (tension/compression); } \\
& G_{f}^{ \pm}=\text {Tensile/compressive fracture energy; } \\
& H \text { = Chemical contribution to the free energy; } \\
& k_{T}=\text { Thermal conductivity; } \\
& K, G=\text { Bulk and shear moduli; } \\
& L=\text { Thermo-mechanical contribution to the free energy; } \\
& n_{T}=\text { Exponent for strength evolution; } \\
& R=\text { Contant for ideal gases; } \\
& R_{\text {ext }}=\text { External volume heat sources; } \\
& Q=\text { Hydration heat per unit volume; } \\
& \bar{Q}_{\infty}=\text { Final ammount of liberated heat (in ideal conditions); } \\
& Q_{\chi}, Q_{\xi}=\text { Hydration heat per unit of hydration extent, degree; } \\
& \boldsymbol{Q}=\text { Heat flux; } \\
& S \text { = Entropy; } \\
& s / c=\text { Silica fume/cement mass ratio; } \\
& T, T_{0}=\text { Temperature, Initial temperature; } \\
& T_{\infty}^{a d}, \bar{T}_{\infty}^{a d}=\text { Final reached temperature in an adiabatic test, } \\
& \text { idem in ideal conditions; } \\
& T_{r} \quad=\text { Reference temperature for maturity calculation; } \\
& T_{\text {ref }}=\text { Reference temperature; } \\
& T_{T}=\text { Maximum temperature for strength evolution; } \\
& V=\text { Thermal contribution to the free energy; } \\
& w / c=\text { Water/cement mass ratio; } \\
& \chi=\text { Hydration extent; } \\
& \chi_{\infty}, \bar{\chi}_{\infty}=\text { Final hydration extent, idem in ideal conditions; } \\
& \eta_{\chi}, \eta_{\chi 0}=\text { Viscosity, Reference viscosity (ref. to } \chi \text { ); } \\
& \eta_{\xi}, \eta_{\xi 0}=\text { Viscosity, Reference viscosity (ref. to } \xi \text { ); } \\
& \bar{\eta}=\text { Exponent for viscosity; } \\
& \kappa=\text { Aging degree; } \\
& \lambda_{E}=\text { Elastic modulus aging function; } \\
& \lambda_{f}^{ \pm}=\text {Tensile/compressive strength aging function; } \\
& \lambda_{G}^{ \pm}=\text {Tensile/compressive fracture energy aging functions; } \\
& \mu_{t}=\text { Maturity; } \\
& \nu=\text { Poisson's ratio; } \\
& \Psi \quad=\text { Free energy; } \\
& \xi, \xi_{\text {set }}=\text { Hydration degree, Hydration degree at setting; } \\
& \xi_{\infty}, \bar{\xi}_{\infty}=\text { Final hydration degree, idem in ideal conditions; }
\end{aligned}
$$

